\title{
Embracing Doubt: Teaching in a Post-digital Age
}

Jan G. Grünwald

"For humans, a state of momentary confusion offers not just frustration but an opening." (Rushkoff, 2019, p. 135)

As already indicated in the title, doubt is an important companion in art education which can certainly be considered productive but is unfortunately often perceived as inhibiting or disruptive (McLaughlin, 2016; Sofatutor Magazin, 2017). This chapter is about a theoretical and educational positioning within art pedagogy, initiated by my own experiences in teaching in different schools and universities, in which I try to indicate options to what extent the topic of doubt can be used productively in the classroom, as well as affirming the uncontrollability of educational processes, and to find appropriate ways to teach in the post-digital age. I will also attempt to show how contemporary aesthetic processes and phenomena like glitch can be used to utilize confusion and embrace the possibility of failure, as well as experimenting with social media as a way to mediate and communicate.

J. G. Grünwald ( $\square)$

University Mozarteum, Innsbruck, Austria

e-mail: jan@gruenwald.name

(C) The Author(s) 2021

K. Tavin et al. (eds.), Post-Digital, Post-Internet Art and Education, Palgrave Studies in Educational Futures, https://doi.org/10.1007/978-3-030-73770-2_15 
Doubt has utopian potential, because it often implies a longing for a different situation (Campbell, 2012; Jha, 2018) and where do we-as art teachers, art educators, researchers, and students-need to believe in utopia if not in education? Here doubt eludes any educational policy or any other kind of logic of exploitation, because in the end no concrete result can be assumed. What is evident, however, is that doubt thinks beyond the present and questions it critically. Thus, I begin with a doubt in order to do justice to the investigation of an art educational position, which is able to deal with the constant changes within the post-digital age. For me, as a pedagogue, it is important to make use of, and to be able to present, concrete situations in which doubt-when looked at in a positive manner-can be used as a means to improve and grow. If we want to create a situation, in which we do justice to the future education of our students, we cannot keep reproducing the power structures of the current system, but instead we have to acknowledge the fact that we-as teachers-just may not know more about our present or future condition than our students and that traditional role models and canons won't be helping much as well. We have to embrace a situation that does justice to our thinking and behavior, which is "messy, confusing, or anomalous" and is, at the same time, "our greatest strength and our greatest defense" against any kind prefabricated approaches (Rushkoff, 2019, p. 135).

The doubt which results from confusion and unknowingness can be turned into a situation in which everyone can (but not must) participate as well as create. It can also be productive to evoke a situation like this, to engage productively within the classroom. For a teacher it can be helpful to follow paths that (1) are not familiar to themselves or to (2) lead to areas of aesthetic production that elude one's own controlled intervention, as well as to (3) involve phenomena that put teachers and students back onto the same level of reception. At the same time, educational processes themselves are ultimately uncontrollable and a space must be created for the possibility of failure, experience, and interchange. The possibility of failure, which is always present in pedagogical processes and which is the basis of doubt, should be affirmed:

We are taught from an early age to experience embarrassment and humiliation when we make mistakes, but good teachers know how to work with our mistakes and strengthen our learning by engaging with those results rather than inculcating our fear of errors. (Peña \& James, 2016, p. 109) 


\section{UNKNOWINGNESS}

Because school has a problem with the new, as art educator Torsten Meyer aptly stated in Next Art Education (2013), and because the new is seldomly the subject of teaching, teachers often find it difficult to perceive doubt and the associated possibility of failure as productive potential. Rather, the still existing subliminal belief in the necessity of a superior teacher-subject as well as the tight time management of the lessons can be reasons why teachers mostly stick to their own abilities and therefore avoid, for example, the confrontation with digital artefacts or collaborative work in (art) lessons, as is common outside of school. In case of excessive doubt - which can also result in an all the more rigid adherence to power relations-one might take a look at Jacques Rancière's book The Ignorant Schoolmaster (1991). In it, Rancière devotes himself to the pedagogue Joseph Jacotot, who in his lessons fundamentally undermines the teacher-student power relationship by having one unknowing person teach another unknowing person what he himself does not yet know. This is about the abolition of the privileged position of explaining: Explaining serves to preserve authority and social relations: "To explain something to someone is first of all to show him he cannot understand it by himself" (Rancière, 1991, p. 6). The world thus becomes divisible into the knowing and the unknowing. Rancière's example does not in any way demand that the pedagogical relationship between teachers and learners should be dissolved, but he does recognize that learners acquire knowledge on their own, while the motivation to acquire it is imparted by the teacher-the unknowing teacher. Isn't the teacher within the postdigital-post-digital meaning a different stage in the perception and use of technology, as well as a critical valuation of the assumptions embedded in the general understanding of the digital ${ }^{1}$ —always an unknowing teacher? Unlike the language barrier in Rancières example, our present and future situation consists of constant change, as well as curating all the information surrounding our everyday lives, and this is what the post-digital emphasizes.

\section{ExPERIMENTS in Social Media}

As a middle and high school teacher, I was ${ }^{2}$ constantly trying to find ways to implement ideas of the post-digital into my work with the students. The students and I curated our own Powerpoint-exhibitions, created 
digital fantasy spaces for our avatars, edited short videos, and tried to find structures of (re)presentation on Instagram. During these couple of years, more and more students tried to follow my private account on Instagram, probably because the students didn't know any other teachers who actually had an Instagram account. I started telling my new classes that I wouldn't befriend any students on my Instagram account and that they shouldn't even try. While working on an Instagram project with my ninth graders, the students asked me to create a teacher's Instagram account so they could follow me. Since I knew that some of my high school students were much more active and experienced than I was, I asked them to become my media team and support me and my teacher's Instagram before going online. They chose the name (@dr_j_green) and taught me about aesthetic consistency, what to put in the stories instead of the timeline, and created green.fact.friday - when each Friday some kind of trivia was shared (whether being personal or professional).

The first thing I did was ask my followers what they wanted to see and read on this Instagram account. They wanted to have an insight into my everyday school life, see art made by their peers, and learn about my interests (art, music, movies, tattoos)-i.e., they wanted to experience another side of one of their teachers. In the following Instagram story, I asked how they would imagine their favorite place for becoming smarter, making experiences and learning if something like school was never invented. From fifth graders to high school students, all participated and envisioned a place that is open to everyone, is not separated by age or school subjects, has neither timetable nor grades, but a collective perspective for a better future. In response to my student's requests, I posted about my life in school, how I prepared my lessons, the artifacts the students' produced, as well as typical ways of communicating on Instagram through selfies, ootd's (outfit of the day) and Memes, but I also posted about my thoughts concerning school, teaching, systemic inequalities and about how to engage in contemporary ways of teaching and the doubts that came with it. In the following months, the Instagram account attracted students form other schools, fellow teachers and many to-be-teachers. I started networking with some of them and we exchanged ideas about teaching methods, how to deal with principals, and how to handle colleagues who present a one sided anti-new-media stance. We also discussed how beneficial it can be to ask students for help with any technical questions we might have and how this leads to not being afraid to ask them for assistance. 
After I finished teaching in schools, content shifted to more university related topics, but is still related to education and the students from my former school are following as well as giving feedback. The Instagram account led to a workshop about post-digital media culture in Cologne ${ }^{3}$ in 2019, where I was invited to share my experiences. During the workshop, I discussed possibilities and difficulties of Instagram for a different take on education with students and teachers alike. The results, which were generated through analyzing teacher-Instagram-accounts as well as one's own user experiences, led to the Account "hacks.4teachers" in which "8 Instagram hacks for teachers" are presented. The hackswhich address teachers of any kind-include tips concerning aesthetics, tagging, content, and frequency for teachers who want to start their own Instagram.

If a teacher interested in the aesthetic as well as structural constitution of Instagram, it is not enough to just post pictures and information of the things they do in class or seminar. When using social media by a person whose field is education, many doubts may arise. If students are interested in the life of a teacher, then how much privacy is appropriate? If one posts information concerning education, how is that achievable in a way that the aesthetics and structures of Instagram are used supportively? Are selfies and memes-which are specific forms of communication in social media-a suitable way to transport or characterize oneself and one's content?

In the @dr_j_green Instagram project I try to find new ways of mediating. As the project is something new to me, I find myself constantly doubting: Questioning what to post and what not to post; how much emphasis should be on me as a person and on information concerning educational content; how much politics should be imparted; what hashtags should be used... This project for me represents what I mentioned before: newness creates doubt (through paths that are not familiar to me), I knowingly put myself in a situation of unknowing and thus I am exercising in a terrain often more familiar to my students.

\section{Disturbances}

Putting yourself in a state of unknowing is also used within processes of aesthetic production. For example by making use of media disturbances to make visible the possibility of failure; meaning the artifact 
gains visibility because it no longer functions in the way users are accustomed to. The same way I gave control to my students to curate the Instagram when I first started it, which made visible for me processes of being represented online and put me (again) in a situation of doubt: some students think that this Instagram failed its original intension (which was to show the work and life of their teacher), but it is exactly this situation of adapting the Instagram account to my current life situation and pedagogical interests, which creates a space (dialectically speaking) maybe closer to that original intension, also by constantly reflecting on the medium I am dealing with and how to use it appropriately. The same way the aesthetic and structural preferences of an app like Instagram often disappear in the process of using it, the hardware disappears in its everyday handling and is completely at the service of what is done with it. The technical device itself becomes conspicuous or emerges from the secrecy of everyday use when it can no longer be used in the way it was intended: The computer, which only comes to the fore when it crashes, or the construction of a low-resolution digital image, which begins to refer to its mediality when its pixels appear. According to Wolfgang Ernst (2009), it is precisely "the disturbances and breakdowns that reveal the nature of a technical practice" (p. 56). At the same time, the uncontrollability of the rebellious medium harbors manifold possibilities for creative debate, e.g., the (in)visibility of things that surround us or ways of making use of disturbances for aesthetic purposes. It is the processes of aestheticization and the artifacts that arise from it that addresses this and thus creates something new from a crashed computer, always reflecting the possibility of failure.

In the following, some examples are discussed to demonstrate how medial disturbances might be used: A whole genre has developed around this so-called "aesthetics of the technical defect," which is often referred to as glitch. The term glitch describes a temporary system error, defect, or bug in an electronic device. This results in disturbed and distorted sounds and images. The notion of lack of control can be seen in the verb "to glitch ," originally defined as "a sudden surge of current," hence "malfunction, hitch" in astronautical slang (Oxford Learner's Dictionary). The term has since evolved to describe unforeseen behaviors within a system, particularly computer systems, as well as video gaming and art among the most prominent. In the case of glitch art, "it has been argued that the lack of control is, more than a circumstance, a desirable ontological condition" (Peña \& James, 2016, p. 112). It can be defined that a glitch is only a 
glitch, if there is no control over the outcome. It is a way to productively deal with the possibility of failure is improvisation; for example, "improvising musicians view errors as a motor of creativity" (Peña \& James, 2016, p. 110).

On his album TTTrial and Eror (date), the musician Apparat uses the signals from his crashing computer to create his music. The disturbing noises oscillate between insect-like whirring, broken sound spaces, and creaking beats. In 2002, when Apparat's album was released the noise he created was a radical approach to sound production (similar to Matmos, who produced an album for Björk and used ice picks to materialize their beats in order to create a feeling of coldness in the sound production). These sounds are by now quite common and completely normal for genres like Clicks \& Cuts. In order to react to the everlasting and ever more rapid exploitation and assimilation-logic of the market, the counter approaches often become not more radical but more subtle.

The musical micro-genre Vaporwave, for example, shows the ambivalence of attempts at demarcation: the irrelevant background music of image films and advertising clips is used, looped, disturbed, and overdrawn. The use of noise is subtle. The soundscape is deliberately trivial and disturbances are only used selectively. An uneasiness of irrelevance is created through subtle shifts and frictions. The listener is constantly asking the question whether Vaporwave is meant as a criticism of the irrelevance of advertising music, in that it is hyper-affirming on the one hand, but still produces slight deviations; or whether it is an uncritical affirmation of catchy music; or whether it is both at the same time? The term Vaporwave itself refers to the fluidity of contemporary capitalism, which can also be found in certain forms of commercial music. The (im)possibility to position oneself critically within an ever-changing, adaptable and quasi all-encompassing system becomes visible, and in the same way always exposes oneself to the danger of merely reproducing the same thing over and over again. Besides the disturbances within the soundscapes of Vaporwave, the genre includes designs, record covers, and even apps ${ }^{4}$ that are strongly related to glitch and its aesthetics of failure.

\section{Pedagogics}

The uncontrollability of the material and the will to explore it improvisationally provides a basis for something new ${ }^{5}$ to appear, as we can see in musical examples mentioned above. Improvisation being central 
to explorations of glitch, "focuses on provoking unpredictable outcomes from routine processes, it requires invention, imagination, and improvisation within a series of imposed technical constraints" (Peña \& James, 2016 , p. 110). On the one hand, the works mentioned above refer directly to the post-digital ${ }^{6}$; at the same time, however, the fictions of a general virtualization of the living world are destroyed, in that the virtual is always thought in relation to the material device, which ultimately is not completely controllable. It is precisely the uncontrollability of these processes and the subsequent need to improvise that offer an interface to education processes. It is about a perpetual renegotiation, in that on the one hand (in terms of content) a thematic area is set up for negotiation and processing, and on the other hand (structurally) a space is enabled for the possibility of failure, experience, improvisation, and change. Robert Poynton (2013) summarizes as follows: "Such a complex world demands an improvised response" (p. 8).

The aforementioned space cannot be defined prior to creating it, precisely because the experience of uncontrollability makes this impossible. The possibility of failure, which is always present in pedagogical processes and which is the basis of doubt, must be affirmed. At the same time, these processes are highly relevant for understanding contemporary cultural and media developments, ranging from material culture, over music and photo production, to social media and photo-apps that have implemented glitch effects. Phenomena like glitch are particularly useful for art education, because they connect to the everyday aesthetic experiences of the students, while always requiring a capacity for reflection; whether that means that we use strategies that force us to improvise, because we don't know what the outcome will be; whether they reference the fact, that all photographic products are digital. The same applies to spaces that are newly developed to enable divergent situations for learning, communication, and collaboration that are also outside of a pedagogical comfort zone, as I am trying to do with the Instagram account.

Doing so, education may become an experience in such a way that spaces of possibility can emerge again and again - often precisely in areas that are beyond one's own access and control. The teachers doubt about their own understanding of these increasingly rapid developments and changes can be transferred into a productive teaching and learning situation through improvisation and questioning power structures, because in the digital age we might not be an all-knowing subject anymore (which 
we never were, of course), but exercising in a terrain often more familiar to our students. This very space gives the possibility to undermine the privileged position of explaining: "the parable of a world divided into knowing minds and ignorant ones, ripe minds and immature ones, the capable and the incapable, the intelligent and the stupid" (Rancière, 1991, p. 8). The will to accept and embrace doubt as a (contemporary) pedagogic situation will strengthen us against any kind of prefabricated approaches, as well as the structural power of explication and may open up a space that goes beyond traditional ways of teaching. Understanding the post-digital condition, with all its manifestations of uncontrollability, may it be contemporary ways of communication, or the creation of unexpected aesthetic artifacts which heavily rely on the materials and immaterials around us, and should not only be seen as a chance for us pedagogues, but is inevitable. The immense problems of schools having to adapt to the situation of the Covid-19 pandemic in 2020 is just one example.

\section{Notes}

1. Also see: (Knox, 2019).

2. I write was, because I no longer work as a schoolteacher, but I am still trying to do the same at university.

3. Entire schedule available here: https://kunst.uni-koeln.de/blog/postdigit ale-medienkultur-in-der-schule/.

4. For example: https://vaporcam.en.aptoide.com/app.

5. Newness should not be understood as a promise, but more as a potentiality (Tavin \& Tervo 2018) as well as in a Deleuzian manner. In Difference and Repetition, Gilles Deleuze states that: "to repeat is to behave in a certain manner, but in relation to something unique or singular which has no equal or equivalent. And perhaps this repetition at the level of external conduct echoes, for its own part, a more secret vibration which animates it, a more profound, internal repetition within the singular" (Deleuze 1994, p. 1).

6. i.e., sounds and pictures no longer are the goal of a creative endeavor, but its source material. As Nicolas Bourriaud (2002) puts it: "The artistic question is no longer: 'what can we make that is new?' but 'how can we make do with what we have?' In other words, how can we produce singularity and meaning from this chaotic mass of objects, names, and references that constitutes our daily life?" (p. 37). 


\section{REFERENCES}

Bourriaud, N. (2002). Postproduction. Lukas \& Sternberg.

Campbell, A. (2012). Why self-doubt is a good thing. https://www.bbc.com/ news/magazine-17689596.

Deleuze, G. (1994). Difference and repetition (Trans. by P. Patton). Columbia University Press.

Ernst, W. (2009). Technologie zeitigt Experimente: Eine Programmatik des Fernsehens. Fernsehexperimente: Stationen eines Mediums, 47-66.

Jha, T. (2018). What if I told you self-doubt is good? https://medium.com/theascent/what-if-i-told-you-self-doubt-is-good-e540226140e.

Knox, J. (2019). What does the 'postdigital' mean for education? Postdigital Science and Education, 357-370.

McLaughlin, M. (2016). How to combat self doubt as a teacher. https://www.tea cher.org/daily/how-combat-self-doubt/.

Meyer, T. (2013). Next art education. Kunstpädagogische Positionen, 29.

Oxford Learner's Dictionary. (2020). Definition of glitch. https://www.oxford learnersdictionaries.com/definition/english/glitch_2.

Peña, E., \& James, K. (2016). A glitch pedagogy: Exquisite error and the appeal of the accidental. Journal of the Canadian Association for Curriculum Studies, 14, 108-127.

Poynton, R. (2013). Do improvise: Less push. More pause. Better results.

Rancière, J. (1991). The ignorant schoolmaster: Five lessons in intellectual emancipation (Trans. by K. Ross). Stanford University Press.

Rushkoff, D. (2019). Team human.

Sofatutor Magazin (2017). Referendariat abbrechen: „Hilfe, ich will keine Lehrerin / kein Lehrer werden!" https://magazin.sofatutor.com/lehrer/refere ndariat-abbrechen-hilfe-ich-will-keine-lehrerin-kein-lehrer-werden/.

Tavin, K., \& Tervo, J. (2018). How soon is now? Post-conditions in art education. Studies in Art Education, 59(4), 282-296. 
Open Access This chapter is licensed under the terms of the Creative Commons Attribution 4.0 International License (http://creativecommons.org/licenses/ by $/ 4.0 /$ ), which permits use, sharing, adaptation, distribution and reproduction in any medium or format, as long as you give appropriate credit to the original author(s) and the source, provide a link to the Creative Commons license and indicate if changes were made.

The images or other third party material in this chapter are included in the chapter's Creative Commons license, unless indicated otherwise in a credit line to the material. If material is not included in the chapter's Creative Commons license and your intended use is not permitted by statutory regulation or exceeds the permitted use, you will need to obtain permission directly from the copyright holder.

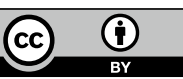

